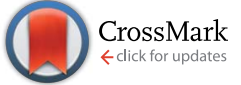

Cite this: J. Anal. At. Spectrom., 2014 29, 2256

Received 17th September 2014 Accepted 7th October 2014

DOI: $10.1039 / c 4 j a 00309 h$

www.rsc.org/jaas

\section{Excitation of higher levels of singly charged copper ions in argon and neon glow discharges}

\author{
Zdeněk Weiss, ${ }^{* a}$ Edward B. M. Steers, ${ }^{b}$ Juliet C. Pickering, ${ }^{c}$ Volker Hoffmann ${ }^{d}$ \\ and Sohail Mushtaq ${ }^{b}$
}

Transition rate diagrams of copper ions in argon and neon glow discharges are presented, using data from $\mathrm{Cu} \|$ emission spectra. Based on the transition rate diagrams, several different collisional processes between ground state and metastable atoms and ions of copper and the discharge gas are proposed as probably significant for populating upper levels of the $\mathrm{Cu} \|$ emission lines observed.

\section{Introduction and experimental details}

Studies of excitation and ionization of copper in glow discharge plasmas have been ongoing for many years, in connection with analytical applications of atomic spectroscopy, hollow cathode lamps, metal vapor ion lasers, magnetron sputtering for thin film deposition and in the diagnostics of astrophysical plasmas. A good introduction to the subject is provided in the works by Zhao and Horlick. ${ }^{1,2}$ The key step to understanding the $\mathrm{Cu}$ II spectrum in argon glow discharges was made by Steers and Fielding in 1987 when they found out that the $224.700 \mathrm{~nm}$ line, by far the strongest $\mathrm{Cu}$ II emission line in a glow discharge in argon, is excited by asymmetric charge transfer between $3 \mathrm{p}^{5}{ }^{2} \mathrm{P}_{1 / 2}$ metastable argon ions and ground state copper atoms: ${ }^{3}$

$$
\mathrm{Cu}_{0}+\mathrm{Ar}_{\mathrm{m}}{ }^{+}\left(3 \mathrm{p}^{5}{ }^{2} \mathrm{P}_{1 / 2}\right) \rightarrow \mathrm{Cu}^{+} *\left(3 \mathrm{~d}^{9} 4 \mathrm{p}^{3} \mathrm{P}_{2}^{\circ}\right)+\mathrm{Ar}_{0}+\Delta E
$$

In this equation and throughout the paper, the asterisk * refers to an excited state of the respective species and the subscripts 0 and $\mathrm{m}$ mean the ground state and a metastable state, respectively. Steers et al. extended the work on $\mathrm{Cu}$ II

${ }^{a}$ LECO Instrumente Plzeň, spol. s r.o., Plaská 66, 32325 Plzeň, Czech Republic. E-mail: weissz@leco.cz

${ }^{b}$ London Metropolitan University, 166-220 Holloway Road, London, N7 8DB, UK

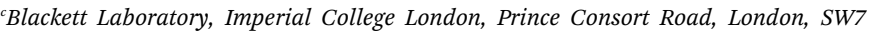
$2 A Z, U K$

${ }^{d}$ Leibniz-Institut für Festkörper-und Werkstoffforschung Dresden, P.O.B. 2701 16, D01171 Dresden, Germany excitation to include a supplementary microwave discharge $e^{4,5}$ and discharges in neon ${ }^{5,6}$ and krypton. ${ }^{6}$ In 1991, Wagatsuma and Hirokawa studied $\mathrm{Cu}$ II spectra in argon-helium glow discharges. ${ }^{7,8}$ The computer modelling of glow discharge excitation of copper in studies by Bogaerts et al. ${ }^{9-11}$ was a remarkable effort. The effects of hydrogen on $\mathrm{Cu}$ II spectra in argon and neon discharges were studied by Hodoroaba et al. ${ }^{12,13}$ and Mushtaq et al. ${ }^{14}$ Matrix effects in glow discharge emission spectroscopy related to the excitation of copper were studied by Weiss. ${ }^{15}$ Classification of selective and non-selective excitation processes in argon-helium plasmas, involving also copper, was presented by Mushtaq et al. ${ }^{16}$ The $\mathrm{Cu}$ II spectrum from a neon discharge is also discussed in a recent study by the same authors. ${ }^{17}$

It was shown very clearly that asymmetric charge transfer (ACT) reactions between copper atoms and ions of argon, neon and helium take place in glow discharges with these discharge gases and produce excited copper ions. ACT is a resonant process $^{1-6}$ and most studies listed above were therefore focused on $\mathrm{Cu}$ II lines with upper levels close to the ionization energy of the discharge gas and lines emitted as a result of cascade deexcitation of such levels. With the exception of the study of Steers and Leis, ${ }^{4}$ the work of Rozsa et al. ${ }^{18}$ and of Mezei et al. ${ }^{19}$ very little attention has been paid to $\mathrm{Cu}$ II levels with higher energies than the ionization energy of the discharge gas and the excitation/ionization processes involved. These higher levels are also excited, although to a much lesser degree. Recently, the formalism of transition rate diagrams (TR diagrams) was proposed by Weiss et al., ${ }^{20,21}$ which makes it possible to investigate quantitatively selective excitation processes in glow discharge spectra and thus identify individual reactions taking place. The present study is an attempt to describe systematically excitation processes in the $\mathrm{Cu}$ II spectrum in argon and neon glow discharges by the corresponding TR diagrams, with emphasis on $\mathrm{Cu}$ II levels with higher energies than the ionization energy of the discharge gas.

The spectral data referred to in this paper come largely from the vacuum-UV high resolution Fourier transform spectrometer 
$(\text { FTS })^{22}$ at Imperial College London, used in conjunction with a free-standing Grimm-type source. Three wavelength ranges were selected by choosing appropriate free spectral ranges and suitable photomutiplier tube detectors and, where needed, optical filters. The combined wavelength range of these FTS measurements was from 151 to $630 \mathrm{~nm}$. The resolution used was: $0.035 \mathrm{~cm}^{-1}$ for the visible region (>365 nm); $0.05 \mathrm{~cm}^{-1}$ for the intermediate region $(250-365 \mathrm{~nm})$, and $0.07 \mathrm{~cm}^{-1}$ for the UV-VUV region (151-250 $\mathrm{nm}$ ). This corresponds to a resolution of $0.14 \mathrm{pm}$ at $200 \mathrm{~nm}$. Radiometric calibration of the FTS spectra was performed using standard lamps, a tungstenhalogen lamp and a deuterium lamp, with known radiation characteristics, and by the branching ratio method. ${ }^{21}$ The procedure will be described in more detail in a forthcoming paper on a new catalogue of glow discharge spectra. Spectral data from two CCD-based glow discharge spectrometers, the LECO GDS500 ${ }^{15}$ at the LECO European Technical Centre, Prague, and the Spectruma GDA650 ${ }^{23}$ at IFW Dresden were also used to give better sensitivity in some wavelength regions. All the measurements mentioned above were made using a Grimmtype glow discharge source ${ }^{20,21,23}$ with a $4 \mathrm{~mm}$ internal anode diameter and a flat cathode (the sample investigated). A dc discharge was used, operating at $700 \mathrm{~V}$ and $20 \mathrm{~mA}$, with the constant voltage-constant current stabilization and pure copper as the cathode. The pressure needed to maintain these conditions was $805 \mathrm{~Pa}$ in argon and $2010 \mathrm{~Pa}$ in neon as the discharge gas.

\section{Results and discussion}

The $\mathrm{Cu}$ II transition rate diagrams resulting from the observed $\mathrm{Cu}$ II spectra in argon and neon glow discharges are in Fig. 1 and 2. The concept of TR diagrams ${ }^{20,21}$ can be described as follows: Intensity $I_{i j}$ of an emission line associated with a radiative transition $i \rightarrow j$ between an upper level $i$ and a lower level $j$ of an atom or ion can be expressed as:

$$
I_{i j}=n_{i \rightarrow j} E_{i j}=n_{i \rightarrow j} \frac{h c}{\lambda_{i j}}
$$

where $\lambda_{i j}$ is the wavelength of this line, $E_{i j}$ is the energy difference between the levels $i$ and $j, n_{i \rightarrow j}$ is the rate of this transition, i.e., the number of such transitions occurring per second. From this equation it follows that the rate $n_{i \rightarrow j}$ is proportional to the product $I_{i j} \lambda_{i j}$. Transition rates associated with different emission lines can thus be evaluated from the observed spectrum, except for a common multiplicative constant. In this sense, the quantities referred to as transition rates are transition rates expressed in an arbitrary unit that is the same throughout the whole paper. Each level $i$ is radiatively depopulated at a rate $R_{i}^{\text {depop }}$ equal to the sum of the rates of all transitions associated with the lines of which $i$ is the upper level and a level $j$ is radiatively populated at a rate $R_{i}^{\text {pop }}$ equal to the sum of the rates of the radiative transitions populating this level, i.e., those transitions for which $j$ is the lower level:

$$
R_{i}^{\text {depop }}=\sum_{k<i} n_{i \rightarrow k} \quad ; R_{i}^{\text {pop }}=\sum_{k>i} n_{k \rightarrow i} .
$$

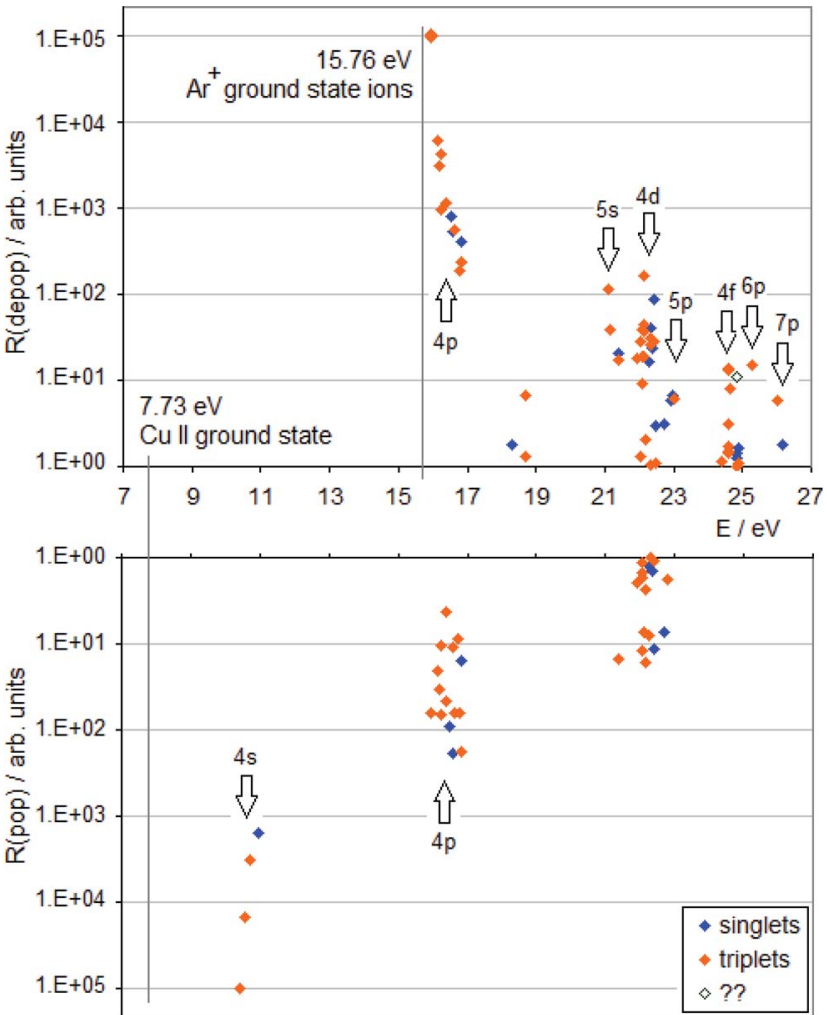

Fig. 1 TR diagram of $\mathrm{Cu} \|$ in argon discharge ( $R(\mathrm{pop})$ is the radiative population rate, $R$ (depop) is the radiative depopulation rate). There are no non-metastable $\mathrm{Cu}^{+}$levels below $15.96 \mathrm{eV}$.

A TR diagram consists of two plots with a common abscissa scale: in the top plot, radiative depopulation rates $\left(R^{\mathrm{depop}}\right)$ of individual levels are plotted as functions of energy, and in the bottom plot, the same is done with radiative population rates $\left(R^{\text {pop }}\right)$, except that the ordinate scale in the bottom plot has values increasing downward, see Fig. 1. The use of TR diagrams to study selective excitation processes is based on the assumption that, in glow discharges, lifetimes of upper states of most observed emission lines are largely limited by radiative decay. Then the rate of collisional excitation of a given state will be equal to the difference between the rate of its radiative deexcitation and the rate of its radiative excitation $\left(R^{\mathrm{col}}\right)$ :

$$
R_{i}^{\mathrm{col}}=R_{i}^{\mathrm{depop}}-R_{i}^{\mathrm{pop}}
$$

Hence, a peak in the top plot of a TR diagram, not balanced by a peak corresponding to the same levels in the bottom plot, indicates that a collisional process is in operation, which selectively populates levels having energies in a vicinity of the peak's position. If there are high transition rates for a given level or group of levels in both plots (top and bottom), it is an indication of a cascade excitation/deexcitation sequence in which this level participates.

To complement the TR diagrams in Fig. 1 and 2, a simplified Grotrian diagram is presented in Fig. 3, showing major radiative deexcitation paths constituting the $\mathrm{Cu}$ II emission spectrum, along with the atomic and ionic ground and metastable states 

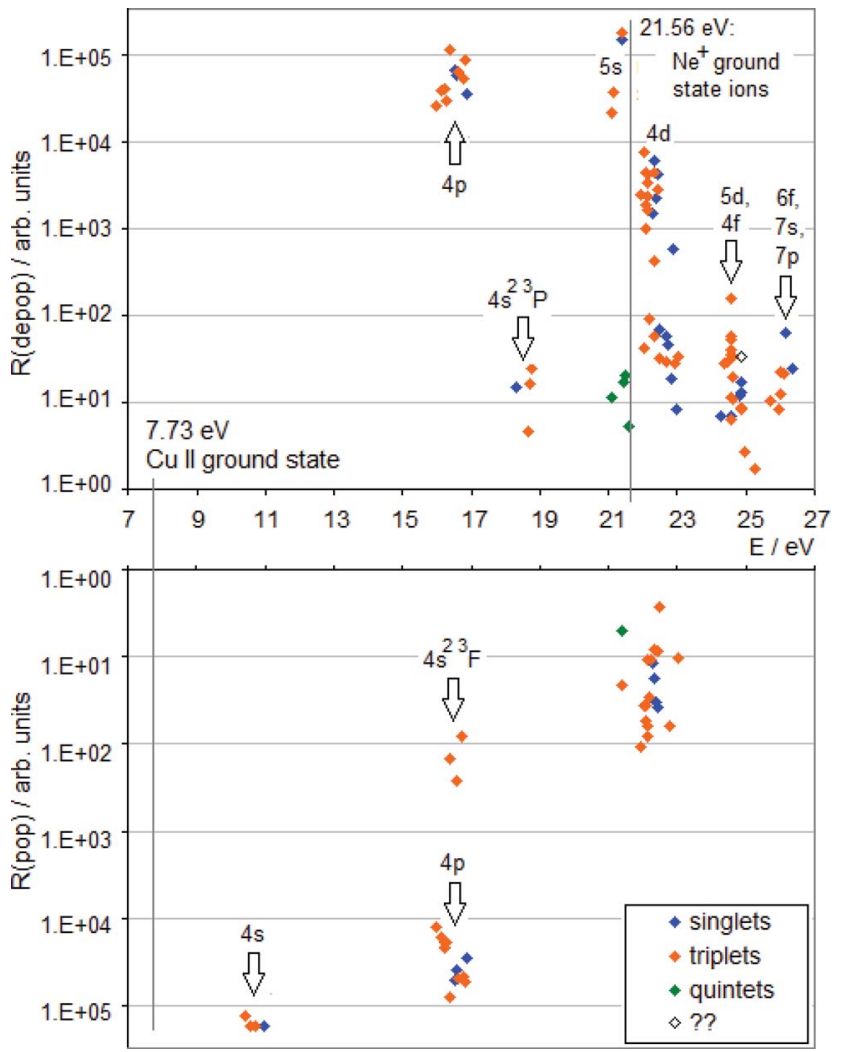

Fig. 2 TR diagram of $\mathrm{Cu} \|$ in neon discharge ( $R(\mathrm{pop})$ is the radiative population rate, $R$ (depop) is the radiative depopulation rate).

of argon and neon. The higher the transition rate observed, the thicker the line used for the corresponding transition or multiplet. Unless otherwise stated, all energies are expressed relative to the ground state of the atom. The lowest $\mathrm{Cu}$ II levels decaying by emission of light belong to the $3 \mathrm{~d}^{9}\left({ }^{2} \mathrm{D}\right) 4 \mathrm{p}$ subshell $(15.96-16.85 \mathrm{eV})$ and their decay populates levels of the $3 \mathrm{~d}^{9}\left({ }^{2} \mathrm{D}\right)$ $4 \mathrm{~s}$ subshell, at $10.45-10.98 \mathrm{eV}$. These levels are metastable, their decay to the $\mathrm{Cu}$ II ground state, $3 \mathrm{~d}^{10}{ }^{1} \mathrm{~S}_{0}$, is both parity and angular momentum-forbidden. The difference between argon and neon discharges concerning the $3 \mathrm{~d}^{9}\left({ }^{2} \mathrm{D}\right) 4 \mathrm{p}$ subshell is that, in argon, the ${ }^{3} \mathrm{P}_{2}^{\circ}$ level of this subshell is populated largely by the $\mathrm{Ar}^{+}-\mathrm{ACT}$ reaction, eqn (1), whilst in neon, there is a very substantial contribution of cascade excitation, affecting all the levels of this subshell, see the TR diagrams in Fig. 1 and 2 . Penning ionization by neon metastables is also likely to contribute to the population of this subshell, as mentioned in, ${ }^{17}$ but only an accurate quantitative analysis of radiative transition rates populating and de-populating this subshell can say how important the Penning ionization is compared to cascading. In a neon discharge, the subshell that is populated almost exclusively by $\mathrm{Ne}^{+}-\mathrm{ACT}$ is the $3 \mathrm{~d}^{9}\left({ }^{2} \mathrm{D}\right) 5 \mathrm{~s}$ subshell, at $21.12-21.37 \mathrm{eV}$.

From the TR diagrams in Fig. 1 and 2, it is clear that, both in argon and neon discharges, there are many $\mathrm{Cu}$ II levels with energies far above the threshold for the corresponding ACT reaction between ground state copper atoms and the ions of the discharge gas used, that are significantly excited, although by $2-4$ orders of magnitude less than the most strongly excited $\mathrm{Cu}$

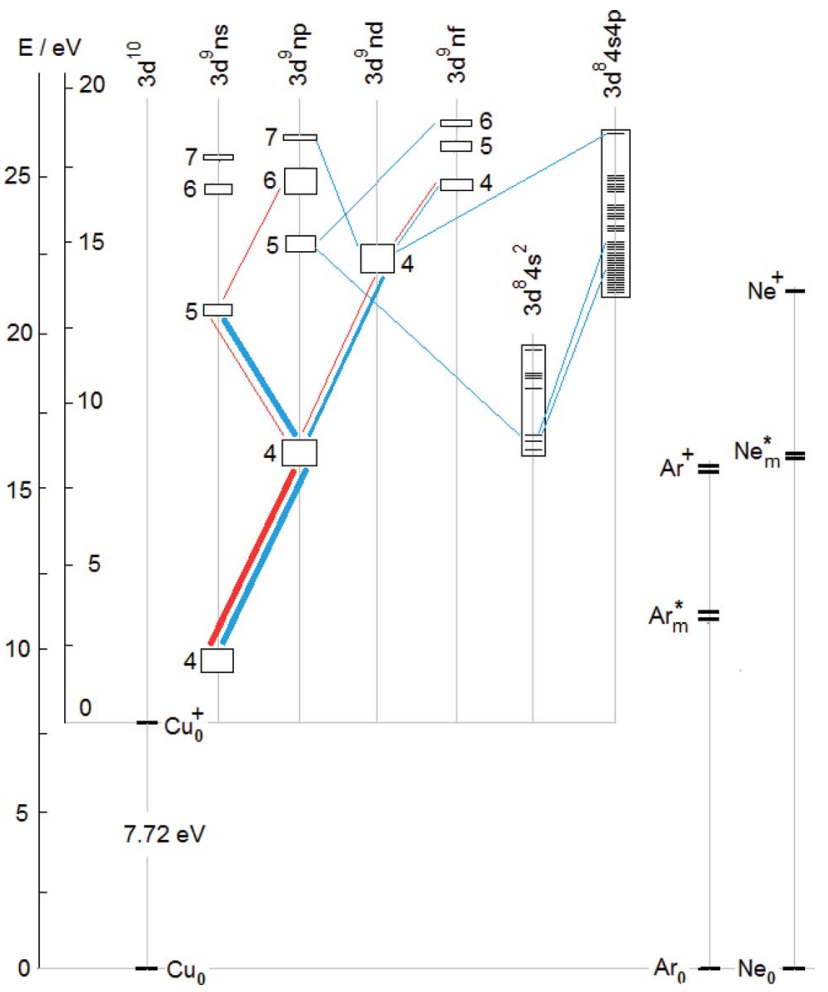

Fig. 3 Major lines and multiplets in the $\mathrm{Cu} \|$ emission spectra in glow discharges in argon (red lines) and neon (blue lines). Left hand energy scale: total excitation energy, right hand energy scale: energy relative to the ground state of the ion.

II levels. Moreover, the observed pattern of radiative deexcitation of the highest $\mathrm{Cu}$ II levels above $\sim 23 \mathrm{eV}$, that are virtually unaffected by cascade processes, is different for both discharge gases. Hence, excitation mechanisms of these levels will be linked to the discharge gas used. It was suggested by Steers et al. ${ }^{3,4}$ that some higher $\mathrm{Cu}$ II levels of the $3 \mathrm{~d}^{9}\left({ }^{2} \mathrm{D}\right) 4 \mathrm{p}$ subshell, up to the energy of $\sim 16.85 \mathrm{eV}$, might be excited by ACT reactions between argon ions and metastable copper atoms with energies significantly above the $\mathrm{Cu}$ I ground state. But this process was then rejected by the authors as rather insignificant in the conventional unboosted dc discharge, based on comparison with a microwave-boosted discharge. The occurrence of many excited $\mathrm{Cu}$ II levels with high energies in the conventional dc discharge prompted us to consider in the present study the whole class of reactions, involving both ground state and metastable copper and argon atoms and ions, as possible excitation mechanisms:

ACT by ground state ion: $\mathrm{Cu}_{0}+\mathrm{X}_{0}^{+} \rightarrow \mathrm{Cu}^{+*}+\mathrm{X}_{0}+\Delta E$

ACT by metastable ion: $\mathrm{Cu}_{0}+\mathrm{X}_{\mathrm{m}}^{+} \rightarrow \mathrm{Cu}^{+*}+\mathrm{X}_{0}+\Delta E$

ACT of metastable $\mathrm{Cu}$ atom: $\mathrm{Cu}_{\mathrm{m}}+\mathrm{X}_{0}{ }^{+} \rightarrow$

$$
\mathrm{Cu}^{+*}+\mathrm{X}_{0}+\Delta E
$$

$\mathrm{ACT}$ of metastable $\mathrm{Cu}$ atom by metastable ion:

$$
\mathrm{Cu}_{\mathrm{m}}+\mathrm{X}_{\mathrm{m}}^{+} \rightarrow \mathrm{Cu}^{+} *+\mathrm{X}_{0}+\Delta E
$$


Penning ionization of ground state $\mathrm{Cu}$ atom:

$$
\mathrm{Cu}_{0}+\mathrm{X}_{\mathrm{m}} \rightarrow \mathrm{Cu}^{+*}+\mathrm{X}_{0}+\mathrm{e}^{-}+\Delta E
$$

Penning ionization of metastable $\mathrm{Cu}$ atom:

$$
\mathrm{Cu}_{\mathrm{m}}+\mathrm{X}_{\mathrm{m}} \rightarrow \mathrm{Cu}^{+*}+\mathrm{X}_{0}+\mathrm{e}^{-}+\Delta E
$$

Penning excitation of ground state $\mathrm{Cu}$ ion:

$$
\mathrm{Cu}_{0}^{+}+\mathrm{X}_{\mathrm{m}} \rightarrow \mathrm{Cu}^{+*}+\mathrm{X}_{0}+\Delta E
$$

Penning excitation of metastable $\mathrm{Cu}$ ion:

$$
\mathrm{Cu}_{\mathrm{m}}^{+}+\mathrm{X}_{\mathrm{m}} \rightarrow \mathrm{Cu}^{+*}+\mathrm{X}_{0}+\Delta E \text {. }
$$

Here $\mathrm{X}$ denotes either $\mathrm{Ar}$ or $\mathrm{Ne}$, depending on which discharge gas is involved. Similarly to ACT, Penning excitation, represented by processes (8), (9), requires a good energy match. A listing of the $\mathrm{Cu}$ in subshells, the excitation of which needs to be explained, is in Table 1, together with reactions suggested to be largely responsible for their excitation. These reactions are defined in Table 2, except for reactions (10), (11), that are

Table 1 Excitation characteristics of the $\mathrm{Cu}^{+}$subshells the transitions from which constitute the $\mathrm{Cu}$ II emission spectrum in $\mathrm{Ar}$ and $\mathrm{Ne}$ glow discharges

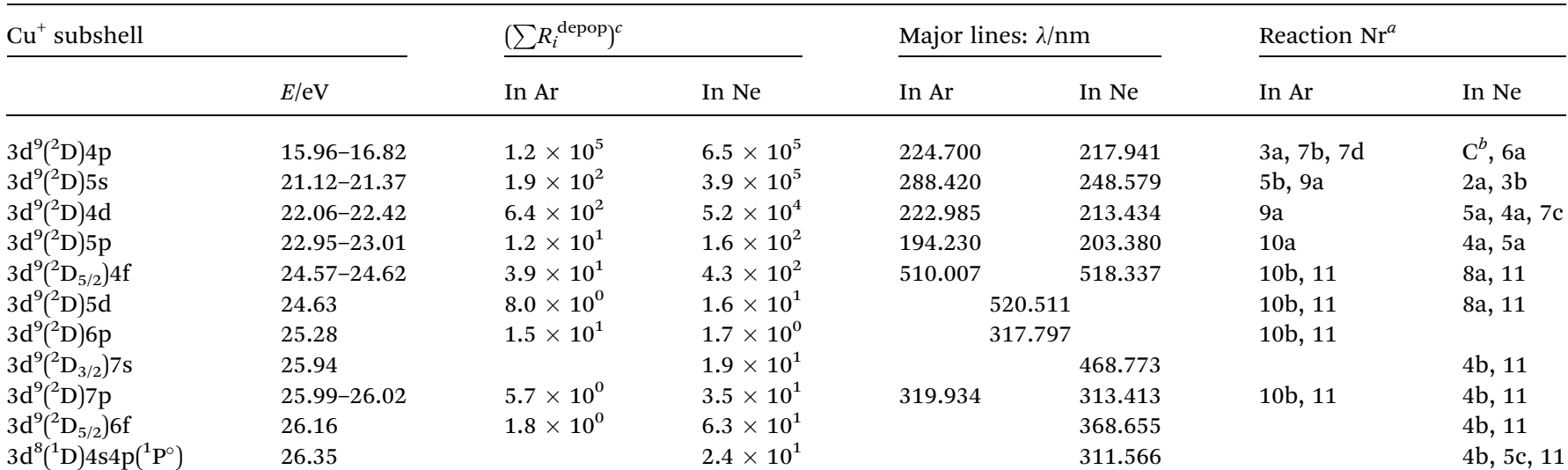

\begin{tabular}{|c|c|c|c|c|c|c|}
\hline & $\mathbf{A r}_{0}^{+}$ & $\mathbf{A r}_{\mathrm{m}}^{+}$ & $\mathbf{A} \mathbf{*}^{b}$ & $\mathbf{N e}_{0}^{+}$ & $\mathbf{N e}_{\mathrm{m}}^{+}$ & $\mathbf{N e} e^{* c}$ \\
\hline & ${ }^{2} \mathrm{P}_{3 / 2}^{\circ}$ & ${ }^{2} \mathrm{P}_{1 / 2}^{\circ}$ & $3 s^{2} 3 p^{5}\left({ }^{2} P^{\circ}\right) 4 s$ & ${ }^{2} \mathrm{P}_{3 / 2}^{\circ}$ & ${ }^{2} \mathrm{P}_{1 / 2}^{\circ}$ & $2 s^{2} 2 p^{5}\left({ }^{2} P^{\circ}\right) 3 s$ \\
\hline$E / \mathrm{eV}$ & 15.76 & 15.94 & $11.55-11.82$ & 21.56 & 21.66 & $16.62-16.84$ \\
\hline
\end{tabular}

${ }^{a}$ Suggested collisional excitation process that is likely to populate this subshell (see Table 2 and the text). ${ }^{b}$ Cascade excitation by radiative decay of some higher levels. ${ }^{c}$ Summation over all states belonging to the given $\mathrm{Cu}^{+}$subshell.

Table 2 Internal energy (in eV) in possible collisions of the second kind that might result in excited $\mathrm{Cu}^{+}$ions listed in Table $1^{a}$

\section{Cu atoms}

$3 \mathrm{~d}^{10} 4 \mathrm{~s}^{2} \mathrm{~S}_{1 / 2}$

$3 \mathrm{~d}^{9} 4 \mathrm{~s}^{2} \mathrm{D}$

$3 d^{9}\left({ }^{2} D\right) 4 s 4 p\left({ }^{3} P^{\circ}\right){ }^{4} P^{\circ}$

$3 d^{9}\left({ }^{2} D\right) 4 s 4 p\left({ }^{3} P^{\circ}\right){ }^{4} F^{\circ}$

$\begin{array}{ll}0.00 & 15.94^{3 \mathrm{a}} \\ 1.39 & \\ 1.64 & \\ 4.84 & \\ 4.97 & \\ 5.08 & \\ 5.10 & \\ 5.15 & \\ 5.25 & \end{array}$

$\mathrm{Cu}^{+}$ions

$3 \mathrm{~d}^{10}{ }^{1} \mathrm{~S}_{0}$

$3 d^{9}\left({ }^{2} \mathrm{D}\right) 4 \mathrm{~s}^{3} \mathrm{D}$
$23.49^{10 \mathrm{a}}$
$26.21^{10 \mathrm{~b}}$
$26.32^{10 \mathrm{~b}}$

7.73
10.45
10.56

10.70

$\begin{aligned} 7.73 & 23.49^{10 \mathrm{a}} \\ 10.45 & 26.21^{10 \mathrm{~b}} \\ 10.56 & 26.32^{10 \mathrm{~b}} \\ 10.70 & \end{aligned}$

$\left(21.09^{5 b}\right)$

$\begin{array}{lllll} & & 21.56^{2 \mathrm{a}} & 21.66^{3 \mathrm{~b}} & 16.62-16.84^{6 \mathrm{a}} \\ & & 22.95^{4 \mathrm{a}} & 23.05^{5 \mathrm{a}} & \\ & & 23.20^{4 \mathrm{a}} & & \\ & 16.38-16.66^{7 \mathrm{~b}} & 26.39^{4 \mathrm{~b}} & 26.49^{5 \mathrm{c}} & \\ & 16.52-16.80^{7 \mathrm{~b}} & 26.53^{4 \mathrm{~b}} & & \\ & 16.63-16.91^{7 \mathrm{~b}} & & & \\ \left(21.09^{5 \mathrm{~b}}\right) & 16.65-16.93^{7 \mathrm{~d}} & & & \\ 21.19^{5 \mathrm{~b}} & 16.70-16.98^{7 \mathrm{~d}} & & & \left(22.09^{7 \mathrm{c}}\right)^{d}\end{array}$

$\left(24.57^{8 \mathrm{a}}\right)^{d}$

${ }^{a}$ The superscripts are the designations of the particular reactions referred to in the last two columns of Table $1 .{ }^{b}$ The same situation occurs as in the case of $\mathrm{Ne}^{*}$, the principal quantum number $\mathrm{n}$ in the $\mathrm{Ar}^{*}$ level designations is higher by one. ${ }^{c}$ Four Ne* $^{*}$ levels are in this energy interval, two of which are metastable: $2 \mathrm{~s}^{2} 2 \mathrm{p}^{5}\left({ }^{2} \mathrm{P}^{\circ}{ }_{3 / 2}\right) 3 \mathrm{~s}^{3} \mathrm{P}_{2}$ and $2 \mathrm{~s}^{2} 2 \mathrm{p}^{5}\left({ }^{2} \mathrm{P}^{\circ}{ }_{1 / 2}\right) 3 \mathrm{~s}^{3} \mathrm{P}_{0}$. The other two, with $J=1$, are also highly populated ${ }^{25,26}$ and can thus contribute to the reactions mentioned here. ${ }^{d}$ Reaction with argon atom in the $3 s^{2} 3 \mathrm{p}^{5}\left({ }^{2} \mathrm{P}^{\circ}{ }_{1 / 2}\right) 4 \mathrm{~s}^{3} \mathrm{P}_{1}$ state or with neon atom in the $2 \mathrm{~s}^{2} 2 \mathrm{p}^{5}\left({ }^{2} \mathrm{P}^{\circ}{ }_{1 / 2}\right) 3 \mathrm{~s}^{3} \mathrm{P}_{1}$ state. 
defined in the text below. In Table 2, the copper ground state and metastable atoms and ions entering the suggested reactions (the first column) are combined with the species related to the discharge gas (the first row) and for each pair of the initial reactants considered, their total internal energy is given in the corresponding cell. Individual reactions are shown in the last two columns of Table 1 and denoted in Table 2 by superscripts attached to the internal energy involved. Each entry consists of a number, specifying the type of the reaction (the number of the corresponding equation above), combined with a letter which defines the reaction unambigously, i.e., is specific for the given pair of reacting species. These species are specified in the header of the column and in the first cell of the row to which the cell showing that reaction belongs. For example, the ACT reaction mentioned in Section 1 and described by eqn (1), responsible for excitation of the $224.700 \mathrm{~nm}$ line, is a special case of the process described by eqn (3) and in Table 2 it has the designation ' $3 a$ '. Similarly, reaction ' $3 b$ ' is the following:

$$
\mathrm{Cu}_{0}+\mathrm{Ne}_{\mathrm{m}}^{+}\left(2 \mathrm{p}^{5}{ }^{2} \mathrm{P}_{1 / 2}\right) \rightarrow \mathrm{Cu}^{+*}\left(3 \mathrm{~d}^{9}\left({ }^{2} \mathrm{D}\right) 5 \mathrm{~s}\right)+\mathrm{Ne}_{0}+\Delta E .
$$

Reactions between reactants differing only in a particular level involved, but belonging to the same term, are classified as identical, i.e., have the same designation (the same superscript) in Tables 1 and 2. Tables 1 and 2 do not contain collisional processes that are not reflected in the $\mathrm{Cu}$ II emission spectrum, such as e.g. the creation of the $\mathrm{Cu}^{+}$ground state and $3 \mathrm{~d}^{9}\left({ }^{2} \mathrm{D}\right) 4 \mathrm{~s}$ metastable ions in an argon discharge by Penning ionization. Also electron impact excitation/ionization is not discussed. Such processes must be accounted for in any complete collisional-radiative models of copper ions in these glow discharges.

What remains to be discussed are the reactions ' $10 \mathrm{a}$ ', '10b' and '11'. In an argon discharge, some $\mathrm{Cu}$ II states with energies greater than $\sim 24 \mathrm{eV}$ are also excited. Such energies are not linked to any reaction mentioned so far. It may be worth to consider the following reaction:

$$
\mathrm{Cu}^{+}+\mathrm{e}^{-}+\mathrm{Ar}^{+} \rightarrow \mathrm{Cu}^{+} *+\mathrm{Ar}_{0}+\Delta E
$$

in which a low energy electron in between $\mathrm{a} \mathrm{Cu}^{+}$and an $\mathrm{Ar}^{+}$ions on a collision trajectory would diminish their electrostatic repulsion and they might form a loosely-bound temporary molecular ion, the decay of which could yield the copper ion excited to the very high energy required. An alternative process would be the neutralisation of $\mathrm{Cu}^{++}$ions,

$$
\mathrm{Cu}^{++}+\mathrm{e}^{-}+\mathrm{Y} \rightarrow \mathrm{Cu}^{+*}+\mathrm{Y}+\Delta E
$$

where $\mathrm{Y}$ is a third body (three-body recombination ${ }^{24}$ ). Further work is being carried out to distinguish between these hypotheses for the excitation in argon discharge of the $\mathrm{Cu}$ II levels with energies around $25 \mathrm{eV}$.

\section{Summary and conclusions}

The $\mathrm{Cu}$ II emission spectra observed in analytical glow discharges in argon and neon with a copper cathode were used to calculate transition rate diagrams of copper ions in these discharges. Based on the TR diagrams, the $\mathrm{Cu}$ II levels excited were identified and 16 different collisional processes ((7) in argon and (9) in neon) between ground state- and metastable atoms and ions of copper and the discharge gas were proposed as probably significant for populating those $\mathrm{Cu}$ II levels. These processes can explain the observed $\mathrm{Cu}$ II spectra to a large extent.

\section{References}

1 Y. Zhao and G. Horlick, Emission spectral characteristics of $\mathrm{Cu}, \mathrm{Ag}, \mathrm{Zn}$ and $\mathrm{Cd}$ neutral atoms in a glow discharge, Spectrochim. Acta, Part B, 2006, 61, 674-685.

2 Y. Zhao and G. Horlick, A spectral study of charge transfer and Penning processes for $\mathrm{Cu}, \mathrm{Zn}, \mathrm{Ag}$ and $\mathrm{Cd}$ in a glow discharge, Spectrochim. Acta, Part B, 2006, 61, 660-673.

3 E. B. M. Steers and R. J. Fielding, Charge-transfer excitation processes in the Grimm lamp, J. Anal. At. Spectrom., 1987, 2, 239-244.

4 E. B. M. Steers and F. Leis, Observations on the use of the microwave-boosted glow discharge lamp and relevant excitation processes, J. Anal. At. Spectrom., 1989, 4, 199-204.

5 E. B. M. Steers and F. Leis, Excitation of the spectra of neutral and singly ionized atoms in the Grimm-type discharge lamp, with and without supplementary microwave excitation, Spectrochim. Acta, Part B, 1991, 46, 527-537.

6 E. B. M. Steers, Charge transfer excitation in glow discharge sources: the spectra of titanium and copper with neon, argon and krypton as plasma gas, J. Anal. At. Spectrom., 1997, 12, 1033-1040.

7 K. Wagatsuma and K. Hirokawa, Spectrometric studies of excitation mechanisms on singly-ionized copper emission lines in Grimm-type glow discharge plasmas with helium mixture technique, Spectrochim. Acta, Part B, 1991, 46, 269281.

$8 \mathrm{~K}$. Wagatsuma and K. Hirokawa, Observation of singlyionized copper emission lines from a Grimm-type glow discharge plasma with argon-helium gas mixtures in a visible wavelength region, Spectrochim. Acta, Part B, 1993, 46, 1039-1044.

9 A. Bogaerts and R. Gijbels, Comparison of argon and neon as discharge gases in a direct-current glow discharge: a mathematical simulation, Spectrochim. Acta, Part B, 1997, 52, 553-565.

10 A. Bogaerts and R. Gijbels, Collisional-radiative model for the sputtered copper atoms and ions in a direct current argon glow discharge, Spectrochim. Acta, Part B, 1998, 53, 1679-1703.

11 A. Bogaerts, Z. Donko, K. Kutasi, G. Bano, N. Pinhao and M. Pinhiero, Comparison of calculated and measured optical emission intensities in a direct current argoncopper glow discharge, Spectrochim. Acta, Part B, 2000, 55, 1465-1479.

12 V.-D. Hodoroaba, V. Hoffmann, E. B. M. Steers and K. Wetzig, Emission spectra of copper and argon in an argon glow discharge containing small quantities of hydrogen, J. Anal. At. Spectrom., 2000, 15, 951-958. 
13 V.-D. Hodoroaba, E. B. M. Steers, V. Hoffmann and K. Wetzig, The effect of small quantities of hydrogen on a glow discharge in neon. Comparison with the argon case, J. Anal. At. Spectrom., 2001, 16, 43-49.

14 S. Mushtaq, E. B. M. Steers, J. C. Pickering and V. Weinstein, Asymmetric charge transfer involving the ions of added gases (oxygen or hydrogen) in Grimm-type glow discharges in argon or neon, J. Anal. At. Spectrom., 2012, 27, 1263-1273.

$15 \mathrm{Z}$. Weiss, Glow discharge excitation and matrix effects in the $\mathrm{Zn}-\mathrm{Al}-\mathrm{Cu}$ system in argon and neon, Spectrochim. Acta, Part B, 2007, 62, 787-798.

16 S. Mushtaq, E. B. M. Steers, J. C. Pickering and K. Putyera, Selective and non-selective excitation/ionization processes in analytical glow discharges: excitation of the ionic spectra in argon/helium mixed plasmas, J. Anal. At. Spectrom., 2014, 29, 681-695.

17 S. Mushtaq, E. B. M. Steers, J. C. Pickering and W. Weinstein, Effect of small quantities of oxygen in a neon glow discharge, J. Anal. At. Spectrom., 2014, 29, 2027-2041.

18 K. Rózsa, P. Mezei, M. Janossy, F. Howarka and J. Kuen, Endoergic charge transfer reactions in the cathode glow, Proceedings of Symp. on At. and Surf. Physics (SASP), Obertraun, Austria, 1986, pp. 263-267.

19 P. Mezei, K. Rózsa, M. Janossy and P. Apai, Endoergic and resonant charge transfer excitation in $\mathrm{He}-\mathrm{Cu}$ discharge, J. Phys. D: Appl. Phys., 1987, 34, 71-74.
20 Z. Weiss, E. B. M. Steers, J. C. Pickering and S. Mushtaq, Transition rate diagrams - A new approach to the study of selective excitation processes: The spectrum of manganese in a Grimm-type glow discharge, Spectrochim. Acta, Part B, 2014, 92, 70-83.

21 Z. Weiss, E. B. M. Steers, J. C. Pickering and S. Mushtaq, Excitation and transition rate diagrams of singly ionized iron in analytical glow discharges in argon, neon and argon-hydrogen mixture, J. Anal. At. Spectrom., 2014, 29, 2078-2090.

22 J. C. Pickering, High resolution Fourier transform spectroscopy with the Imperial College (IC) UV-FT spectrometer, and its applications to astrophysics and atmospheric physics: a review, Vib. Spectrosc., 2002, 29, 2743.

23 S. Mushtaq, V. Hoffmann, E. B. M. Steers and J. C. Pickering, Comparison of a sample containing oxide with a pure sample with argon-oxygen mixtures, J. Anal. At. Spectrom., 2012, 27, 1423-1431.

24 B. Chapman, Glow Discharge Processes, J. Wiley, 1980.

25 C. E. Light, A study of spectral line intensities and excited atom populations in a hollow cathode discharge, $\mathrm{PhD}$ thesis, Council for National Academic Awards, 1989.

26 R. Djulgerova, D. Jechev, Y. Pacheva and S. Rashev, On the population of neon levels in the low temperature plasma of a hollow cathode discharge, Spectrosc. Lett., 1975, 8, 1001-1008. 